\title{
The role of the organizational culture of trust in the formation of regional social capital
}

\author{
Marina Alexandrovna Kolmykova $^{{ }^{*}}$ and Elena Nikolaevna Korneeva ${ }^{2,3}$ \\ ${ }^{1}$ Orenburg State University, Department of State and Municipal Administration, Orenburg, Russia \\ ${ }^{2}$ Financial University under the Government of the Russian Federation, Department of Mass \\ Communications and Media Business, Moscow, Russia \\ ${ }^{3}$ Togliatti State University, Department of Master's Degree Programs (Business Programs), Togliatti, \\ Russia
}

\begin{abstract}
The article discusses the problem of reducing the level of trust in various social institutions, including public authorities. It is shown that this problem is an obstacle to the formation of regional social capital. The research purpose is to determine the role of the organizational culture of trust in the process of formation and accumulation of regional social capital. Based on the study, it was found that the integrated level of trust is most observed in the social institution of the family, and the lowest one in the social institution of the state, this confirms the tendency of a significant decrease in the level of trust in public authorities and, in turn, this prevents the accumulation of social capital in regions. It has been established that today regions face socio-economic challenges, namely: a pandemic, digitalization of social relations, changes in the labor market, the outflow of talented young people to the capital universities, brain drain, "anti-human factor" in enterprises. It is assumed that the most rational response to the challenges will be the development of regional social capital through the organizational culture of trust in enterprises. Moreover, regional social capital can be considered as a set of social capital of citizens with a pro-active attitude, inspiring political leaders, as well as public figures, and social capital of enterprises which organizational culture is based on trust. The article notes that the formation of the organizational culture of trust can contribute to a decrease in staff turnover, an increase in labor productivity, personnel involvement, an increase in the competitiveness of an enterprise, organizational commitment, an increase in business reputation.
\end{abstract}

Keywords: organizational culture, social capital, trust, regional social capital

\section{Introduction}

The process of social capital formation is complex and ambiguous, therefore, it is necessary to study it at the macro and micro levels. Social capital at these levels generally appears in

\footnotetext{
${ }^{*}$ Corresponding author: mari kol@mail.ru
} 
the form of public goods, which are produced and sold in a collective way. It is worth noting that each of them has distinctive features. It is advisable to refer to the opinion of foreign and domestic scientists who conducted research on the essence of the relationship between the categories of "trust" and "organizational culture". In this study, it is of certain interest, since it is possible to get a more detailed understanding of the role of the organizational culture of trust in the process of social capital formation.

It is necessary to pay attention to the research of Pescha, which focuses on the development phases of the element of trust in an organization. The research data contains a description of the calculation phase, the information-experimental phase and the identity phase. Any phase has its own characteristics. For example, the first phase is characterized by the slow development and disappearance in the event of a wrong action by an object of trust. The second phase contains components of regularity and systematicity of partners' meetings. The final stage of this phase implies a feeling of sympathy between partners. Moreover, both partners are already ready for mutual assistance, even if they have to incur damage to the assisting party [1].

At the very beginning, a team leader's trust in his subordinates, the working group is formed. Members of the working group simultaneously begin to build trusting relationships with each other. The result of this process is the formation of team members' trust in their leader. Honesty, professionalism, responsiveness, seniority and other aspects affect the strength of trusting relationships in an organization. As soon as the team leader is convinced that there is a certain level of trust in the organization, he will learn to trust himself.

Pescha's position is worthy of close attention, since the researcher analyzes the category of "trust" within the organizational culture, as well as its impact on performance. It should be noted that the above levels of trust, which are formed in the organization, are rationally appropriate for the theory of organizational culture by Schein, since he considered it as a tool of internal integration and external adaptation in the organization [2].

The interconnection of organizational culture and social capital is expressed in the fact that the formation of a positive corporate image and reputation of an organization through the establishment of trusting relationships with suppliers, partners and customers acts simultaneously as a tool of external adaptation and non-organizational social capital [3].

The successful activity of each enterprise is undoubtedly determined by the managerial actions of a team leader. He recruits employees to his organization, is directly involved in the creation of the working group. Consequently, the formation of the organizational culture of an enterprise occurs when the management of the enterprise is focused on people, their teamwork, progressive and stable activities [4].

It has been proven that a team leader is a subjective factor that predetermines the uniqueness of the organizational culture, which excludes the appointment of random persons (special education, experience in management activities in the management system, recommendations, personal qualities and personality traits, etc.) $[5,6]$.

In the process of choosing leadership styles, three important components can be distinguished that underlie the overall portrait of a team leader: personality traits, leadership style and authority, which affect the effectiveness of team leadership as a whole and, ultimately, the processes of forming a psychological climate [7].

Scientists have identified the main qualities of management culture associated with the successful enterprise performance. Primarily, this includes the support of the enterprise management of the organizational culture, which is aimed at increasing the value of each employee, as well as his creative potential [8]. This definitely forms the trust of subordinates in their leader and vice versa. 
It should be borne in mind that an employee's satisfaction with his professional activities directly affects the performance of an entire organization [9]. The fact that job satisfaction is observed in the majority of employees may indicate a certain level of trust within the working group.

The research purpose is to determine the role of trust in the process of formation and accumulation of regional social capital.

To achieve this purpose, it is necessary to solve the following tasks:

1) to conduct an expert survey among the heads of enterprises and institutions of the Orenburg region to determine the integrated level of trust in various social institutions;

2) to conduct focus groups with representatives of the management of budgetary organizations and authorities of the Orenburg region, as well as with heads of departments and representatives of the top management of commercial organizations in the region;

3 ) determination of the role of trust in the process of formation and accumulation of regional social capital.

\section{Methods}

Based on the research purpose, in order to collect information, a decision was made to conduct an empirical study, consisting in an expert survey among heads of enterprises and institutions of the Orenburg region and conducting focus groups. The study used quantitative research methodology to collect and analyze the interpretations and values of the questionnaire.

When conducting focus groups, the authors proceeded from the need to analyze the opinions of heads of enterprises and institutions on the process of formation and development of regional social capital, as well as the determination of its role in the socio-economic development of the Orenburg region.

The first group included representatives of the management of budgetary organizations and authorities of the Orenburg region, the second one - heads of departments and representatives of the top management of commercial organizations in the region. The criterion for this selection is due to the fact that the heads of various enterprises and institutions in the region may have a special view and depth of understanding of the topic of social capital and the way it affects the regional development.

\section{$3 \quad$ Results}

In this study, it was decided to analyze the social relationships that are characteristic of various social institutions. It is also necessary to establish a possible level of trust as an integrated one.

It was found that this level of trust is most observed in the social institution of the family. Based on the opinion of representatives of Orenburg enterprises and institutions, a ranked list of manifestations of the integrated level of trust in the studied social institutions was formed.

Ranking the level of trust in social institutions:

1. Family;

2. Education;

3. Economy;

4. Health care;

5. Business; 


\section{State.}

It can be observed that the experts attributed the lowest integrated level of trust to the social institution of the state. Within the framework of this study, team leaders were asked to assess the challenges facing each region that directly or indirectly affect the decrease in the integrated level of trust in various social institutions and hinder the accumulation of social capital. The main challenges were socio-economic ones: a pandemic, digitalization of social relations, changes in the labor market, the outflow of talented young people to the capital universities, "brain drain", "anti-human factor" in enterprises.

\section{Discussion}

In the authors' opinion, the most rational response to the challenges facing the socio-economic development will be the development of regional social capital through the organizational culture of trust in enterprises.

Human and social capital can be generally viewed as two human assets that exist within the development of a particular community. There are also assumptions that human capital includes "the skills and knowledge obtained in formal and informal learning". Consequently, the formation and development of these skills contribute to the broader social development of any of the communities [10].

At first glance, it may seem that the considered forms of capital are interconnected, they complement and reinforce each other, but there is a clear border between them. It should be borne in mind that human capital is embodied in people, while social capital is embodied in relationships between them [11].

In turn, social capital can be viewed from the perspective of a multidimensional system, which consists of structural, relational and cognitive aspects. That is why social capital often explains "how people perform better because they are somehow better connected to other people", and better networks predict business success [12].

The second dimension of social capital is a relational dimension. It has been suggested that this dimension of social capital is mainly related to ideas of trust, standards, identification and commitment, which facilitate coordination actions and reduce opportunism. Basically, the relational dimension is needed to acquire new knowledge. It also promotes social cohesion [13].

The third dimension of social capital is a cognitive dimension. It directly concerns language and narratives in the communication process, which create a common or mutual understanding in a relationship. A shared understanding and shared goals not only provide information to the parties, but also influence the perception of the relationship [14].

Currently, the above types of dimensions of social capital have become even more relevant, since there is an urgent need to determine the role of organizational culture and trust in the formation of social capital of a region as a whole. It should be noted that increasing the level of trust in a region is a rather problematic task.

It is necessary to pay attention to a certain paradox in society, on the one hand, trust in the authorities has been undermined and there is a decrease in social solidarity in society, on the other hand, the Russian mentality is a powerful tool that unites people. An example is the multiplicity of manifestations of social solidarity during the Great Patriotic War. Or the situation during the perestroika period, when people were not paid a salary for six months, but they remained loyal to the organizations they worked for, and were part of them despite everything [15]. This instills confidence that the accumulation of social capital in the regions will give the necessary impetus to the socio-economic development of the territories. 
The modern world is characterized by new waves of changes in Russian society. There is an expansion of digitalization in the national economy simultaneously with the impact of digitalization on the life of each organization. This is the conclusion made by researchers of the leading international management consulting company "Oliver Wyman". In their research, they view organizational culture as a long-term system of beliefs, values and expectations. Researchers also argue that organizational culture is formed in the process of development of an organization when it adapts to the conditions of the external environment, as well as in the process of the organization's internal architecture [16].

Adapting to new realities for all enterprises and institutions is a paramount task, which is solved in different ways. In the authors' opinion, each organization in the region should form its own organizational culture of trust, which, in turn, should become a competitive advantage of an organization and will contribute to the accumulation of intra-organizational and extra-organizational social capital, which is also the basis for accumulating social capital in each region.

\section{Conclusion}

The formation of the organizational culture of trust can contribute to: reducing staff turnover, increasing labor productivity, staff involvement, increasing the competitiveness of an enterprise, organizational commitment, increasing business reputation.

The basic factor of the socio-economic development of a region is reflected in formal and informal relations between various organizations. The development of mutual trust in the region leads to an increase in the level of trust in the authorities as a whole. For this reason, there is an accumulation of social capital and an increase in the competitiveness of the region.

Regional social capital can be considered as the aggregate of social capital of individuals and legal entities. In other words, regional social capital, on the one hand, consists of social capital of citizens with a pro-active attitude, outstanding political leaders, as well as public figures who have gained authority among the public. On the other hand, the second element is social capital of enterprises, which organizational culture is based on trust. Therefore, the rational development of each of the elements is so important to get rich regional social capital as a result.

\section{References}

1. A.V. Pesha, Naukovedenie, 9(2), 100EVN217 (2017)

2. E. Schein, Organizatsionnaya kultura i liderstvo [Organizational culture and leadership], V.A. Spivak (ed) (Piter, St. Petersburg, 2002)

3. M.A. Kolmykova, Bul Samara Munic Inst Manag, 2, 102-109 (2020)

4. Y.O. Da Silva, A. Firdiansjah, B. Triatmanto, Int J Adv Sci Res Eng, 5(3), 110-115 (2019). http://doi.org/10.31695/IJASRE.2019.33113

5. M.H. Rahman, T. Dey, M. Al-Amin, Asian Bus Rev, 9(1), 17-22 (2019). http://doi.org/10.18034/abr.v9i1.221

6. W. Cai, E.I. Lysova, S.N. Khapova, B.A.G. Bossink, Front Psychol 9, 1767 (2018). http://doi.org/10.3389/fpsyg.2018.01767

7. T.A. Dukhina, Hist Soc-Edu Thought, 8(1(2)), 104-144 (2016). http://doi.org/10.17748/2075-9908-2016-8-1/2-140-144 
8. S.K. Tran, Int J Corp Soc Resp, 2, 10 (2017). https://doi.org/10.1186/s40991-017-0021-0

9. B.A. Soomro, N. Shah, South Asian J Bus Stud, 8(3), 266-282 (2019). https://doi.org/10.1108/SAJBS-12-2018-0142.

10. J. Jackson, A. Carden, R.A. Compton, App Econ, 47(65), 5853-5867 (2015). https://doi.org/10.1080/00036846.2015.1058912

11. M. Moore, N. Recker, Loc Gov Stud, 41(6), 881-897, (2015). https://doi.org/10.1080/03003930.2015.1050092

12. R.S. Burt, K. Burzynska, Manag Org Rev, 13(2), 221-260 (2017). https://doi.org/10.1017/mor.2017.6

13. D.Z. Levin, J. Walter, M. M. Appleyard, R. Cross, Group Org Manag, 41(4), 415-457 (2016). https://doi.org/10.1177/1059601115574429

14. S. Madhavaram, S.D. Hunt, J Bus Res, 74(1), 38-46 (2017). http://doi.org/10.1016/j.jbusres.2017.01.007

15. A.G. Tyurikov, Human. Fin Univ Bul, 2, 51-53 (2018). https://doi.org/10.26794/2226-7867-2018-8-2-51-53

16. O. Wyman, Corporate culture in Russia: new horizons of transformation (2019). Accessed on: October 8, 2021. [Online]. Available: https://www.oliverwyman.com/content/dam/oliver-wyman/europe/ru/files/corporate-cu lture-in-russia.pdf 